\title{
Evaluation of Hepatitis C Surveillance in Washington State
}

\author{
Natalie Linton* \\ Washington State Department of Health, Shoreline, WA, USA
}

\section{Objective}

To evaluate the surveillance system for hepatitis $\mathrm{C}$ virus in Washington State using the Centers for Disease Control and Prevention guidelines for evaluating public health surveillance systems. Based on the findings of the evaluation, recommendations will be made for changes in practice.

\section{Introduction}

Hepatitis $\mathrm{C}$ is a nationally notifiable viral infection that occurs as a result of parenteral contact with infected body fluids. An estimated 3.5 million persons are currently infected with $\mathrm{HCV} .{ }^{1}$ Infection status is divided into acute (short-term, onset within 6 month of exposure) and chronic (long-term). For most people (75-85\%), acute HCV infection leads to chronic infection. ${ }^{2}$ Those with chronic infection remain relatively asymptomatic until the infection becomes severe enough to be recognized or the infected individual is screened for infection with hepatitis C. Major causes of morbidity and mortality associated with $\mathrm{HCV}$ are liver cirrhosis and hepatocellular carcinoma. Treatment is available, but it is expensive and not recommended for some vulnerable populations, such as those with ongoing injection drug use (IDU), who account for the majority of new HCV infections in the United States..$^{3-5}$ Washington State records cases of both acute and chronic HCV infection, but the system is fragmented.

\section{Methods}

The evaluation will involve key informant interviews as well as review of data respositories such as the Public Health Issue Management System in order to assess the simplicity, flexibility, data quality, acceptability, sensitivity, positive predictive value, representativeness, timeliness, and stability of HCV surveillance in Washington State.

\section{Results}

The evaluation is currently in progress. Preliminary results are expected by November 2015 .

\section{Conclusions}

The findings of this surveillance evaluation will inform the restructuring of other state and local HCV surveillance systems. Improved surveillance and care can lead to reductions in the incidence of cirrhosis, hepatocellular carcinoma, and liver transplantation as well as prevent transmission.

\section{Keywords}

surveillance evaluation; hepatitis $\mathrm{C}$; $\mathrm{HCV}$

\section{Acknowledgments}

Office of Communicable Disease Epidemiology, Washington State Department of Health, Shoreline, WA; Office of Infectious Disease, Washington State Department of Health, Tumwater, WA; Scott Lindquist, State Epidemiologist, Washington State Department of Health.

\section{References}

${ }^{1}$ Edlin BR. Towards a more accurate estimate of the prevalence of hepatitis C in the United States. Hepatology. 2015 Jul 14; doi: 10.1002/ hep.27978. [Epub ahead of print]

${ }^{2}$ Thomas DL, Seeff LB. The natural history of hepatitis C. Clin Liver Dis. 2005 Aug;9(3):383-98, vi.

${ }^{3}$ Mehta S, Genberg B, Astemborski J, et al. Limited uptake of hepatitis $\mathrm{C}$ treatment among injection drug users. J Community Health 2008;33:126-33.

${ }^{4}$ Hagan H, Latka MH, Campbell JV, et al. Eligibility for treatment of hepatitis $\mathrm{C}$ virus infection among young injection drug users in $3 \mathrm{US}$ cities. Clin Infect Dis. 2006;42(5):669-67.

${ }^{5}$ Grebely J, Haire B, Taylor LE, et al. Excluding people who use drugs or alcohol from access to hepatitis $\mathrm{C}$ treatments - Is this fair, given the available data?. J Hepatology. 2015 Aug 4; doi: 10.1016/j. jhep.2015.06.014. [Epub ahead of print]

\section{*Natalie Linton}

E-mail: natalie.linton@doh.wa.gov 